manage patients afterward (with lifestyle advice and oral therapy ${ }^{3,4}$ ) is potentially huge.

The prospect of targeted screening (as supported by Lyon and associates) warrants consideration. Screening tools with different predictive abilities $(75 \%$ to $80 \%$ sensitivity and $50 \%$ to $76 \%$ specificity $\left.{ }^{5,6}\right)$ are available, which could be used anywhere in the community. These tools take into account major risk factors such as family history, exercise levels, age, body mass index, waist circumference, dietary habits, medication history and history of dysglycemia; however, they perform poorly as standalone tests. ${ }^{7}$

A 2- or 3-stage screening test (e.g., the combination of a questionnaire and random capillary blood glucose testing, which yields 58\% sensitivity and 94\% specificity $^{8}$ ) might be a more efficient use of resources, ensuring that OGTTs are not performed unnecessarily. Other combinations of near-patient tests and scoring tools that might be used in community settings should be studied, similar to the successful assessment in local pharmacies of people at risk of hypertension. ${ }^{9}$ It would be entirely possible, using a mixture of community-based measurements such as scoring tools for diabetes risk, fasting capillary blood glucose readings and near-patient testing of hemoglobin $\mathrm{A}_{1 c}$ to target individuals who should undergo an OGTT. This might reduce the potential burden on both laboratories and family physicians.

\section{Gina Agarwal}

Assistant Professor

Department of Family Medicine

McMaster University

Hamilton, Ont.

\section{References}

1. Lyon AW, Larsen ET, Edwards AL. The impact of new guidelines for glucose tolerance testing on clinical practice and laboratory services. CMA7 2004;171(9):1067-9.

2. Harris MI, Klein R, Wellborn TA, Knuiman MW. Onset of NIDDM occurs at least 4-7 years before clinical diagnosis. Diabetes Care 1992;15:815-9.

3. Chiasson JL, Josse RG, Gomis R, Hanefeld M, Karasik A, Laakso M. Acarbose for prevention of type 2 diabetes mellitus: the STOP-NIDDM randomised trial. Lancet 2002;359(9323):2072-7.

4. Knowler WC, Barrett-Connor E, Fowler SE,
Hamman RF, Lachin JM, Walker EA, et al; Diabetes Prevention Program Research Group. Reduction in the incidence of type 2 diabetes with lifestyle and metformin. N Engl 7 Med 2002;346 (6):393-403.

5. Rolka DB, Narayan KM, Thompson TJ, Goldman D, Lindenmayer J, Alich K, et al. Performance of recommended screening tests for undiagnosed diabetes and dysglycemia. Diabetes Care 2001;24:1899-903

6. Lindstrom J, Tuomilehto J. The diabetes risk score: a practical tool to predict type 2 diabetes risk. Diabetes Care 2003;26(3):725-31.

7. Engelgau MM, Narayan KMV, Herman WH. Screening for type 2 diabetes. Diabetes Care 2000;23(10):1563-80.

8. Peters AL, Davidson MB, Schriger DL, Hasselblad V. A clinical approach for the diagnosis of diabetes mellitus: an analysis using glycosylated hemoglobin levels. Meta-Analysis Research Group on the Diagnosis of Diabetes Using Glycated Hemoglobin Levels [published erratum appears in 7AMA 1997;277:1125]. 7AMA 1996; 276:1246-52.

9. Kaczorowski J, Karwalajtys T, Chambers L, Levitt C, Dolovich L, McDonough B, et al. Community strategies to monitor high blood pressure among older adults [abstract]. Pharmacy Practice Research Symposium; 2002 Feb 1; Toronto.

DOI:10.1503/cmaj.1041724

\section{Clinical trial budgets}

Tn May 1991, Ian Rusted chaired a 2day workshop sponsored by the $\mathrm{Na}-$ tional Council on Bioethics in Human Research (now the National Council on Ethics in Human Research) entitled "Ethics of Clinical Trials for Research Ethics Boards."' The participants were representatives of the pharmaceutical industry, the Medical Research Council of Canada, Health and Welfare Canada and the Royal College of Physicians and Surgeons of Canada, as well as members of research ethics boards from across Canada.

On reading the viewpoint by Lorraine Ferris and David Naylor, ${ }^{2}$ the spirited response by Salim Yusuf ${ }^{3}$ and the rebuttal by Ferris and Naylor, ${ }^{4}$ I experienced a sense of déjà vu: the points of view expressed in this exchange mirror the conclusions of the 1991 workshop. Unfortunately, although the TriCouncil drafting committee had access to the workshop recommendations for financial accountability and conflict of interest, they were not incorporated in the Tri-Council policy statement. ${ }^{5}$ The authors and CMAJ are to be commended for revisiting the subject.
At the heart of the matter are issues critical to both patient care and clinical research. Both of these activities are dependent upon public trust, which must be earned through openness and integrity.

\section{Gerald A. Klassen}

Retired Physician

Centreville, NS

\section{References}

1. Bioethics when undertaking clinical trials. In: Ethics of clinical trials for research ethics boards: proceedings of a national workshop. NCBHR Communiqué 1991;2(2):19-23.

2. Ferris LE, Naylor CD. Physician remuneration in inudstry-sponsored clinical trials: the case for standardized clinical trial budgets [editorial]. CMA7 2004;171(8):883-6.

3. Yusuf S. Randomized clinical trials: Slow death by a thousand unnecessary policies? [editorial]. CMA7 2004;171(8):889-92.

4. Ferris LE, Naylor CD. Rebuttal [editorial]. CMA7 2004;171(8):892-3.

5. Tri-Council policy statement: etbical conduct for research involving humans. Ottawa: Medical Research Council of Canada; Natural Sciences and Engineering Research Council of Canada; Social Sciences and Humanities Research Council 1998. Available: www.ncehr-cnerh.org/english /code_2/ (accessed 2005 Jan 5).

Competing interests: Dr. Klassen is a past president of Canadian Society for Clinical Investigation and $\mathrm{Na}$ tional Council on Ethics in Human Research.

DOI:10.1503/cmaj.1041672

W e commend Salim Yusuf for his reply ${ }^{1}$ to the call by Lorraine Ferris and David Naylor ${ }^{2}$ for additional monitoring of clinical trials. Yusuf's point on the increasing complexity of regulation for clinical trial research is well taken, as is the point that complying with complex regulations creates significant costs. Although one of us (J.A.C.D.) has previously argued against an excessive reliance on clinical trials, ${ }^{3}$ it is clear that they represent the modern gold standard. Given this reality, it is essential that we not choke off this important type of research.

Increasing costs through the requirement to deal with nontransparent and complex regulations actually makes it harder for independent researchers to do research. We have recently seen the consequences of restricting clinical trials to large drug companies ${ }^{4}$ rather than independent academic investigators. It would seem more appropriate to have well-trained auditors who could iden- 